\title{
Statistical Analysis of Urban Quality of Life (Case Study: Hawassa Town, SNNP Region, Ethiopia)
}

\author{
Natnael Mamuye*, Bute Gotu \\ Department of Statistics, College of Natural and Computational Sciences, Samara University, Samara, Ethiopia
}

Email address:

naty.buna@gmail.com (N. Mamuye),belamh2015@yahoo.com (B. Gotu)

\section{To cite this article:}

Natnael Mamuye, Bute Gotu. Statistical Analysis of Urban Quality of Life (Case Study: Hawassa Town, SNNP Region, Ethiopia). American Journal of Theoretical and Applied Statistics. Vol. 4, No. 6, 2015, pp. 547-554. doi: 10.11648/j.ajtas.20150406.26

\begin{abstract}
The study on Quality of life in the cities of both developing and developed countries is gaining interest from a variety of disciplines and is becoming an important tool for policy evaluation, rating of cities, urban planning and management. Cities are the center of economy, politics, commerce and other activities, so it is necessary to analyze the conditions that contribute to the quality of urban life. This study is on urban quality of life of the residents in Hawassa city and its main purpose is to identify the factors that may affect the quality of life of Hawassa residents. For the study a cross sectional data from 570 heads of household which were selected based on stratified random sampling by making the seven sub cities in Hawassa as stratum was collected. Statistical methods such as descriptive statistics, factor analysis and binary logistic regression are used to analyze the data in the study. The principal component analysis revealed that six factors (dimensions) of quality of life were extracted from twenty subjective attributes and all of the factor scores are positively and significantly related to quality of life. Factor analysis also extracts six factors using fifteen objective attributes. Housing, length of residence, economic status, distance from educational center and religious place all have statistically significant impact on people's quality of life in Hawassa. But access to public service is not significant predictor of quality of life of the residents in Hawassa. Housing, economic condition, environment, neighborhood safety and security, social connectedness and quality of public service are identified as dimensions of subjective quality of life of the residents in Hawassa. The paper also conclude that socio-economic affairs, access to public service, access to education, housing, access to religious place and length of residency are found to be the dimensions of the objective quality of life of the residents in Hawassa.
\end{abstract}

Keywords: Quality of Life, Subjective, Objective, Logistic Regression, Hawassa

\section{Background}

The study on the quality of life in the cities of both developing and developed countries is gaining interest from a variety of disciplines such as planning, geography, sociology, economics, psychology, political science, behavioral medicine, marketing and management [1,2], and is becoming an important tool for policy evaluation, rating of places, urban planning and management.

The term "quality of life" is used to indicate the general well-being of residents and societies. It is often associated with the term "standard of living" but the two do not necessarily mean the same. A standard of living merely is the evaluation of the wealth and employment status of a person in a society. Though both are factors to determine quality of life, these are not its sole indicator. A person's environment, physical and mental health, education, recreation, social well-being, freedom, human rights and happiness are also significant factors.

Urban quality of life can be measured objectively or subjectively. Objectively, quality of life is measured using objective indicators which are related to observable facts that are derived from secondary data. Example of secondary data include population density, crime rate, level of education, unemployment rate, household income, traffic accident, house hold characteristics etc.

Subjectively, quality of life is measured by using subjective indicators which tries to measure and quantify the citizen's satisfaction from the urban welfare. For instance satisfaction of residents from health care accessibility, satisfaction on access to job, satisfaction of urban security or satisfaction from access to housing, satisfaction toward cost of living etc.

Using both objective and subjective measures of quality of life, previous studies have examined the association between the two. Some studies claim no significant effects of the 
former on the latter, while others have found that improved objective domains contribute to higher over all individual satisfaction of life as whole [3].

The concept of quality of life is complex, not easily defined in agreeable terms and not much studied in the Ethiopian context. In the Ethiopian context quality of life mainly refers to the availability of resources and goals to satisfy basic needs [4]. According to Aklilu and Dessalegne's [5] residents' satisfaction on their life has to do with having farm land, cattle, farm implements and a house in rural settings. It is having some job (employment) or business (some income) in the urban setting.

As few studies are available on quality of life in Ethiopia, this study intends to fill this gap with focus on Hawassa, capital of southern nations, nationalities and peoples region. Hawassa is the only really big urban center in the region, and during the last dozen years it has grown substantially in size and economic activity [6].

Thus in this study, the quality of life of the residents in Hawassa was measured by using both subjective and objective attributes. Different statistical methods have been used to analyze the primary data. Factor analysis is used to reduce the number of dimensions of both subjective and objective quality of life into few, which are unrelated to each other. Binary logistic regression is also applied to identify the most significant factors that can affect quality of life in the area.

\section{Methods}

\subsection{Description of the Study Area}

This study has been conducted in Hawassa Town, capital of Southern Nations Nationalities and Peoples Region, Ethiopia from January 2011 to July 2011. Hawassa is situated at eastern shore of Lake Hawassa in the Great Rift Valley. Geographically it lays between $7^{\circ} 3^{\prime}$ latitude North and $38^{\circ} 28^{\prime}$ longitude East [7]. The altitude of the city is $1697 \mathrm{~m}$ above sea level [6]. Hawassa city is bounded by Lake Hawassa in the west, Oromia region in the north, Wondogenet wereda in the east and Shembedino wereda in the south.

The city administration has an area of 157.2 square kilo meters, divided into 8 sub cities and 32 "kebele". The eight sub cities are Hayek Dare, Menaharia, Tabor, Misrak, Bahil Adarash, Addis Ketema, Hawella-Tula, and Mehal sub-city. According to Abinet's report the estimated population size of Hawassa town in 2002 E.C is 183,027 out of which 94,366 are male and the rest $(88,661)$ are female [7].

\subsection{Population and Sampling Technique}

The target population for this study was those households who live in Hawassa town and a combination of two sampling technique were used in these study. These methods were; stratified random sampling and systematic random sampling. Stratified random sampling was first applied by considering the 7 sub-cities as strata. Then residential houses from each sub-cities were selected by using systematic random sampling and finally one individual (household heads) in each selected residential house was required to fill the questionnaire.

\subsection{Sample Size Determination}

In this study stratified random sampling was used and the sample size determination formula that adopted in this study was Cochran [8]:

$$
n=\frac{\sum_{i=1}^{k} \frac{N_{i}^{2} p(1-p)}{w_{i}}}{\frac{N^{2} e^{2}}{Z^{2}}+N p(1-p)}
$$

Thus $\mathrm{p}$ (proportion of success) $=0.37$ was used in these study to determine the sample size from previous study [9] and The level of precision in this study was $4 \%$ at $5 \%$ significance level that is, $\mathrm{e}=0.04$ and $\alpha=0.05$.

Finally, by using the total number of households in Hawassa ( $\mathrm{N}=24041$, the sample size for the study was computed to be 544. And 5 percent of the sample size, which was 27 , was added to compensate for none response rate. Thus, the required sample size for this study was 571 household heads from 24041 residential houses.

\subsection{Methods of Data Collection}

In this study only primary data was used which is cross-sectional data that has been obtained by preparing questionnaire and distributing it to the randomly selected samples in each stratum or sub city. Data collection was carried out using trained data collectors under the supervision of the researcher who worked closely with them. The questionnaire is adopted from previous similar works by making some slight modification based on the thesis objective and study area characteristics.

\subsection{Data Analysis}

The data were directly entered into and coded in SPSS version 16. Different statistical methods have been used for the analysis: descriptive statistics, Factor analysis, binary logistic regression were used to analyze the collected data. Descriptive analysis provided general information about the subject population. Multivariate analysis allowed for data reduction through exploratory factor analysis and binary logistic regression used those factors which are obtained from factor analysis to see the relation they have with quality of life of the residents.

\subsection{Ethical Considerations}

Ethical clearance was obtained from the ethical review committee of the Department of statistics of Hawassa University. Protection of the rights of the study participants was ensured by giving them due freedom to participate in the study or not to participate. Privacy and confidentiality were maintained during the interview

\section{Results}

\subsection{Individual and Household Charactersitics}

A sample of 543 respondents from 7 subcities of Hawassa was collected to achieve the main objective of this study. A 
four point likert scale ranged from 0 to 3 is used to measure individual's responce on their quality of life, domain satisfaction and its attributies;a scale of 0 represents very dissatisfied, 1 represents dissatisfied, 2 represents satisfied and 3 represents highly satisfied for the subjective quality of life and domain satisfaction.

Among the respondents $56.7 \%$ of them are males. The respondents age ranges from 18 to 73 with mean 39.5 and standard deviation 9.95. Interms of marital status, the majority of the head of the household (69.6\%) are married. Educational charactersitics of the heads of the households shows that the majority $(85.5 \%)$ are litrate while only $14.5 \%$ are ilitrate. It was observed that some $20.1 \%$ attained education up to secondary level.

The household characteristics i.e. household size, number of dependent children and family income of the respondents were also known. Accordingly more than $57 \%$ of the respondents live in a family having more than 5 persons and about $3 \%$ of the respondent's family has more than three dependent individuals. In terms of monthly income, $18.2 \%$ of the respondent's family earns less than 500 Ethiopian birr while only $2.6 \%$ will get monthly income of more than 4501 and about half of the respondents $(51.2 \%)$ are private home owners.

\subsection{Summary of Intuitive and Rational Quality of Life}

The subjective quality of life is measured by either intiutive response or rational response. The intiutive subjective quality of life in the city is meaured by asking respondents what they feel about their life as whole during the time of the household survey i.e 2011 and two years before the time of the house hold survey. But the rational subjective quality of life is the integreted satisfaction of individuals with domains of life and is computed after individuls were asked about their satisfaction with specific domains of life.

When respondents were asked about their life, about $31.1 \%$ express their dissatisfaction while only $9.2 \%$ of respondents are highly satisfied with their life. When the respondents were asked their feeling about their life before two years, the majority of them $(43.6 \%)$ said they were satisfied with their life while only $6.4 \%$ of the respondents were very dissatisfied with their life.Respondents were also asked their level of satisfaction with the selected domains of life, and the overall quality of life have been computed based on the response. The idea that quality of life could be conceptualized as a composite of more specific domain measures has been pursued by many researchers. Thus, the domain of life identified for this study are housing, built enviromnent, neighborhood safety, neighborhood sanitation, quality of puplic servise, access to puplic servises, social connectedness, family income and cost of living. Percentage of respondents in each level of domain satisfaction, the mean and standard deviation of each domain satifaction are shown in Table 1.

Table 1. Descriptive Statistics for Domain Satisfaction at the City Level (Hawassa, 2011).

\begin{tabular}{llllllllll}
\hline \multirow{2}{*}{ Level of satisfaction } & \multicolumn{2}{l}{ domain of life(\%) } & & & & & & \\
\cline { 2 - 10 } & HH & BE & NS & SF & AC & PS & SC & FI & CL \\
\hline Very dissatisfied & 8.8 & 3.9 & 8.3 & 4.8 & 8.5 & 12.3 & 13.4 & 27.1 \\
Dissatisfied & 26.5 & 32.8 & 46.6 & 39.8 & 39.5 & 44 & 30 & 37.6 & 39 \\
Satisfied & 43.5 & 50.3 & 38.1 & 39.6 & 47.1 & 40.3 & 44.4 & 28.5 & 5.3 \\
Highly satisfied & 21.2 & 13.1 & 7 & 15.8 & 4.8 & 3.3 & 12.2 & 6.8 & 1.3 \\
Mean & 1.76 & 1.72 & 1.43 & 1.66 & 1.48 & 1.34 & 1.55 & 1.15 & .53 \\
Mode & 2 & 2 & 1 & 1 & 2 & 1 & 2 & 1 & 0 \\
Standard deviation & .88 & .73 & .74 & .79 & .71 & .73 & .87 & .89 & .65 \\
\hline
\end{tabular}

$\mathrm{HH}=$ housing, $\mathrm{BE}=$ built enviromnent, $\mathrm{NS}=$ neighborhood sanitation, $\mathrm{SF}=$ neighborhood safety, $\mathrm{AC}=$ acces to puplic servise, $\mathrm{PS}=$ quality of puplic servise, $\mathrm{SC}=\mathrm{social}$ connectedness, $\mathrm{FI}=$ family income, $\mathrm{CL}=$ cost of living

Table 2. Percentage of Intiutive QOL score for 2009 and 2011 (Hawassa, 2011).

\begin{tabular}{lllll}
\hline \multirow{2}{*}{ Level of QOL } & \multicolumn{2}{l}{ Satisfaction on quality of life in 2011 } & \multicolumn{2}{l}{ Satisfaction on quality of life in 2009 } \\
\cline { 2 - 5 } & Percentage (\%) & Commulative & Percentage (\%) & Commulative \\
\hline Very dissatisfied & 27.3 & 27.3 & 6.4 & 6.4 \\
Dissatisfied & 31.3 & 58.6 & 35.4 & 41.8 \\
Satisfied & 32.2 & 90.8 & 43.6 & 100.0 \\
Highly satisfied & 9.2 & 100.0 & 14.5 & \\
Mean(likert) & 1.23 & & 1.66 & \\
Mode & 2 & & 2 & .8 \\
Standard deviation & .95 & & & \\
\hline
\end{tabular}

Small percentage of respondents felt dissatisfied or felt worst in housing and built enviromnent while less than half of the respondents felt dissatisfied or worst in neighborhood safety, social connectedness and acces to puplic servise. More than half of the respondents felt dissatisfied or worst in three of the nine domains. These domains are;neighborhood sanitation, quality of puplic servise and family income. Only
$6.6 \%$ of the respondents are satisfied with cost of living. As shown in the Table the mean satisfaction score also varies. The most favorable evaluated domain interms of mean score is housing and the least favorable domain is cost of living.

The rational quality of life with two levels is then computed from the selected domains of life. Table2 indicates the percentage of respondents in Hawassa that are categorized in 
the two levels are almost proportional (50.8\% of respondents were unsatisfied while $49.2 \%$ were satiesfied with their life as whole).

The overall quality of life at the sub city level was also measured. About $75 \%$ of the respondents from Mehal sub city express their dissatisfaction on their current quality of life and about $61.5 \%$ of respondents from Menaharia sub city express their highest satisfaction on their current quality of life in the city.

\subsection{Factor Analysis for the Reduction of Subjective Attributes}

Multivariate analysis in the form of factor (principal components) was conducted on all subjective quality of life attributes of each domain. Before factor analysis is conducted, the reliabilities of the variables (data) were checked against the recommended standards (Cronbach $\alpha \geq 0.70$ ) mainly to ensure that they are reliable indicators of the constructs. The data set was checked and it met the criteria for Bartlett's Test of Sphericity. Since the P-value (.000) is less than the test of significance $(\alpha=.05)$ and the Kaiser-Meyer-Olkin (KMO) measure of sampling adequacy is 0.833 which is greater than 0.5 (greater than. 05) indicating that there are probably significant relationships among attributes of the subjective quality of life and hence data are suitable for factor analysis.

Table 3. Factor Loading Matrix for the Reduction of Subjective Attributes.

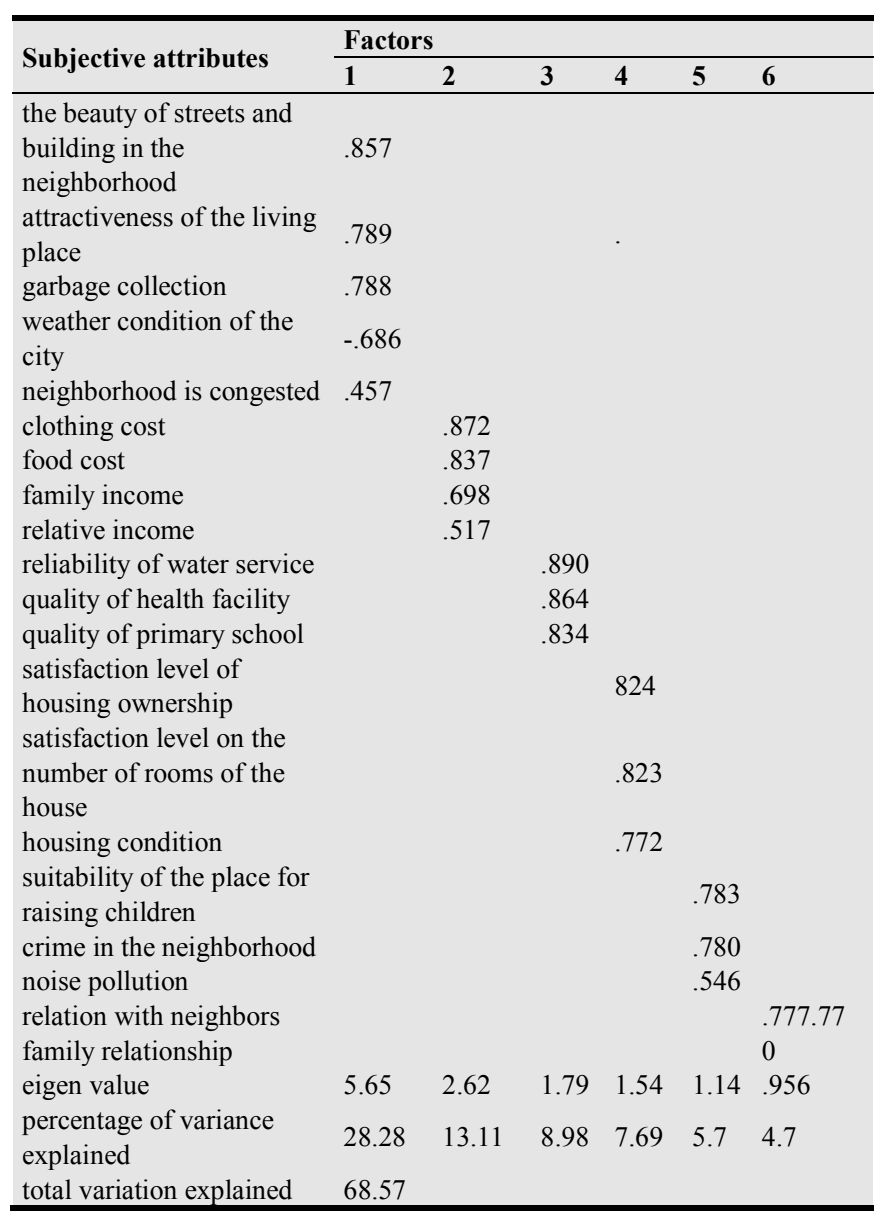

Table 3 displays the items and factor loadings for the rotated factors, with loadings less than 0.45 omitted to improve clarity.

A comparison between the variables (attributes) of the six factors and the attributes of domains of life for the subjective part of the household survey and the physical meaning for each factor is given below.

First factor: This mostly shows high loading on attributes of neighborhood sanitation which was included in the questionnaire and can be labeled as neighborhood sanitation dimension of subjective quality of life.

Second factor: The second factor mainly consists of attributes from cost of living domain that were included in the questionnaire. In addition family income and relative income which was grouped under income domain is included in this factor. Thus it is termed as economic dimension of subjective quality of life.

Third factor: This factor mostly shows high loading on attributes of quality of public service which were included in the questionnaire. Thus this factor is labeled as quality of public services dimension of subjective quality of life.

Fourth factor: Housing condition, number of rooms of the house and housing ownership are all attribute related to the living home and this can be named as housing dimension of subjective quality of life.

Fifth factor: This factor mainly consists of attributes from neighborhood safety and built environment which were included in the questionnaire and it can be named as environmental dimension of subjective quality of life.

Sixth factor: family relationship and relation of the household with neighbors are the only attributes which have high loadings with this factor and therefore it can be labeled as social relation dimension of subjective quality of life.

\subsection{Binary Logistic Regression for the Relation Between Overall QOL and Subjective Domains Score}

Binary logistic regression is applied to assess the relationship between overall quality of life which is dichotomized response variable (unsatisfied /satisfied) and domain scores which are obtained from the factor analysis of subjective attributes. SPSS version 15 is used to perform binary logistic regression by making the unsatisfied level as reference category. Before applying the final multiple logistic regression models with 6 covariates for the intended purpose it has to be assessed and diagnosed for all possible model inadequacies.

The classification table, Hosmer and Lemeshow test and model summary table all indicates that the fitted model with 6 covariates is satisfactory. The multiple logistic regression coefficients can be estimated using the maximum likelihood estimation method implemented in the SPSS package.

All factor scores are significant at 5\% level of significance (table 4).The odds ratio and confidence interval for economic domain is 3.33(95\% CI is in b/n 2.54 and 4.37 ), for quality of public service was $2.71(95 \% \mathrm{CI}$ is in $\mathrm{b} / \mathrm{n} 2.09$ and 3.50$)$, neighborhood sanitation $1.86(95 \% \mathrm{CI}$ is in $\mathrm{b} / \mathrm{n} 1.47$ and 2.36$)$, for housing was $2.05(95 \% \mathrm{CI}$ is in $\mathrm{b} / \mathrm{n} 1.61$ and 2.62$)$, for 
environmental domain $2.05(95 \% \mathrm{CI}$ is in $\mathrm{b} / \mathrm{n} 1.60$ and 2.63$)$ and for social connectedness was 2.19 (CI is in b/n 1.73 and 2.78). These indicate that with a one point increase on; quality of public service domain score, economic domain score, neighborhood sanitation domain score, housing domain score, environment domain score and social connectedness domain score is being associated with the odds of satisfying with life as whole increasing by a multiplicative factor $2.71,3.33,1.86$, $2.05,2.05$ and 2.19 respectively.

Table 4. Variables in the Equation for the Relationship between Overall Quality of Life and Subjective Domains Score.

\begin{tabular}{|c|c|c|c|c|c|c|c|}
\hline \multirow{2}{*}{ Covariates } & \multirow{2}{*}{ B } & \multirow{2}{*}{ S.E. } & \multirow{2}{*}{ Wald } & \multirow{2}{*}{ Sig. } & \multirow{2}{*}{$\operatorname{Exp}(B)$} & \multicolumn{2}{|c|}{$95.0 \%$ CI for $\operatorname{EXP}(B)$} \\
\hline & & & & & & Lower & Upper \\
\hline Quality of public service & .997 & .131 & 58.089 & .000 & 2.710 & 2.097 & 3.502 \\
\hline Neighborhood sanitation & .625 & .120 & 27.324 & .000 & 1.868 & 1.478 & 2.361 \\
\hline Housing & .722 & .124 & 33.632 & .000 & 2.058 & 1.612 & 2.626 \\
\hline Safety and security & .721 & .127 & 32.351 & .000 & 2.056 & 1.604 & 2.636 \\
\hline Constant & .010 & .113 & .008 & .928 & 1.010 & & \\
\hline
\end{tabular}

\subsection{Factor Analysis for the Reduction of Objective Attributes}

There are several objective attributes (variables) that may affect quality of life. Factor analysis is first applied to know the dimensions of the objective QOL. Fifteen variables which reflect both household and individual characteristics are studied. The data set was checked and it met the criteria for Bartlett's Test of Sphericity, since the P value (.000) is less than the test of significance $(\alpha=.05)$ and the Kaiser-Meyer-Olkin (KMO) measure of sampling adequacy is 0.708 which is greater than 0.7 indicating that there are probably significant relationships among attributes of the objective QOL and this in turn implies that the data set is suitable for factor analysis.

Both the scree plot and the eigen values support the conclusion that these 15 attributes can be reduced to six components. The scree plot flattens out after the sixth component. The six factors are interpreted as to define the objective quality of life in the Hawassa city as follows.

First factor: This factor shows high loadings on household size and number of dependent children, family income and educational level. Thus it can be named as socio-economic domain of objective quality of life

Second factor: This factor has high loadings on distance of the house: from police station, main shopping area and from health care facilities. And thus, it can be named as access to public service dimension of objective quality of life.

Third factor: This factor has high loadings on distance of the house from primary school and secondary school. And thus, it can be named as access to education dimension of objective quality of life

Fourth factor: this factor can be interpreted as housing dimension of objective quality of life since it shows high loadings on housing tenure and number of rooms per house.

Fifth factor: The fifth factor contains distance of the house from spiritual place and frequency of church (mosque) attendance. Since this attributes shows religious affiliation of an individual it can be labeled as religious (spirituality) dimension of objective quality of life.
Sixth factors: age and years in Hawassa are the two variables which makes up of the sixth factor. These variables express the stability characteristics of individuals. So it can be named as the length of residency dimension of objective quality of life.

\subsection{Binary Logistic Regression for the Relation Between Overall QOL and Objective Domains Score}

Binary logistic regression is also applied to assess the relationship between overall quality of life which is dichotomized response variable (unsatisfied /satisfied) and domain scores which are obtained from the factor analysis of objective attributes.

Before running the main output, the adequacy of the model has to be tested. From the results of the classification table, Hosmer and Lemeshow test and model summary table, it can conclude that the fitted model with six covariates is satisfactory. The multiple logistic regression coefficients can be estimated using the maximum likelihood estimation method implemented in the SPSS package.

Table 5 shows that five factor scores out of six are significant at $5 \%$ level of significance. The odds ratio and confidence interval for socio-economic status.31 (95\% CI $=$. 245-.392), for access to education 0.743 (95\% CI=.60-.909), for housing was $1.69(95 \% \mathrm{CI}=1.37-2.086)$, for access for religious place. $704(95 \% \mathrm{CI}=.571-.866)$ and length of residency was $1.524(\mathrm{CI}=1.232-1.884)$. The values for instance indicate that with a one point increase in: housing domain score and length of residency domain score is being associated with the odds of satisfying with life as whole increasing by a multiplicative factor of 1.69 and 1.52 respectively. On the other hand, a one unit change in the independent variable (socio-economic status domain score, distance of educational centers domain score, distance of religious place domain score ) increase the odds of being satisfied with their life as whole by $0.31,0.712$ and 0.704 respectively. That is dissatisfaction on overall quality of life is associated with travelling long to get educational centers and religious place. Having large number family size and number of dependent person is also associated with low quality of life. 
Table 5. Variables in the Equation for the Relationship between overall QOL and Objective Domain Scores.

\begin{tabular}{|c|c|c|c|c|c|c|c|}
\hline \multirow{2}{*}{ Covariates } & \multirow{2}{*}{ B } & \multirow{2}{*}{ S.E. } & \multirow{2}{*}{ Wald } & \multirow{2}{*}{ Sig. } & \multirow{2}{*}{$\operatorname{Exp}(B)$} & \multicolumn{2}{|c|}{$95.0 \%$ CI for EXP(B) } \\
\hline & & & & & & Lower & Upper \\
\hline Socio-economic & -1.160 & .120 & 93.533 & .000 & .314 & .248 & .397 \\
\hline Access to public service & -.172 & .106 & 2.608 & .106 & .842 & .683 & 1.037 \\
\hline Access to education & -.297 & .103 & 8.338 & .004 & .743 & .607 & .909 \\
\hline Housing & .527 & .106 & 24.562 & .000 & 1.693 & 1.375 & 2.086 \\
\hline Access to Religious place & -.389 & .107 & 13.356 & .000 & .677 & .550 & .835 \\
\hline Length of residency & .421 & .108 & 15.111 & .000 & 1.524 & 1.232 & 1.884 \\
\hline
\end{tabular}

\section{Discussion}

In previous sections, the dimensions of subjective quality of life and the relation with the overall quality of life were assessed. In addition, the dimensions of objective quality of life were identified. The relation between the objective quality of life dimensions score and overall qualities of life were also considered.

The results indicate that residents' quality of life is often measured by either intuitive or rational responses. The intuitive response reflects individual satisfaction with life without considering the integrated satisfaction with domains of life. However the rational (overall) quality of life is an integrated individual's satisfaction with domains of life. As stated by Elsa [9] comparing the two responses can help to apply more accurate quality of life measurements.

In this study a difference is observed in the level of quality of life that is measured based on intuitive and rational responses. The rational response resulted in larger percentage of respondents that are satisfied in life than that of the intuitive response. For rational response, the percentage of respondents who are satisfied with life is $50.8 \%$ while only $49.2 \%$ of respondents are unsatisfied with life. The difference is about $8.5 \%$ and it may be due to the fact that intuitive response is instinctive and not well thought. The respondents may also focus on some aspects of life while replying their intuitive responses. The result agrees with the finding by Elsa [9] and Ibrahim and Chung [10] that reported higher percentage of respondents that are satisfied in terms of rational response than intuitive response for the selected settlements in Krikos sub city of Addis Ababa and Singapore respectively.

In this study intuitive QOL is measured and compared with two years, i.e. 2011 and 2009. This helps to evaluate the progress in QOL through years. There is difference in QOL for the two years in Hawassa. The percentage of respondents that feels dissatisfied in their QOL for 2011 is larger than that of 2009. One of the main reasons may be the economic crisis in recent years which is expected to influence the respondents feeling. This result is also similar to the finding of Elsa [9].

Respondents were also asked to rate their level of satisfaction with the domain of life identified for this study. In general respondents were most satisfied with housing and built environment. This could be due to the fact that many respondents are able to live in their own home. And respondents were feeling dissatisfied or worst with cost of living. This could be due to the rise of price of some items in recent years.

Elsa [9] reported that respondents were most satisfied with social connectedness and least satisfied with monthly income in Krikos sub city of Addis Abeba. Ibrahim and Chung [10] also reported that respondents were most satisfied with public safety and least satisfied with the environment in industrial area in Singapore. Mojtaba [11] also revealed that the people of Sonqor city were highly satisfied with housing domain and were least satisfied with recreation. According to Akram [12] the residents of Rostamabad city were fairly satisfied with entertainment and sewerage network but relatively less satisfied with other services.

The difference in results of different areas may be due to the difference in type and numbers of domains selected, and the contents of the study in different area are not the same. For instance, Elsa [9] did not include cost of living for which most of the respondents express dissatisfaction in this study.

The paper also tries to identify the dimensions of subjective quality of life in the city by using principal component of factor analysis. The 20 variables are reduced to 6 factors following the factor analysis. The factors are named as housing domain score, economic domain score, environmental domain score, neighborhood safety and security domain score, social connectedness domain score and quality of public service domain score.

A simplified model of overall quality of life is then developed by using the six domain score as independent variables through binary logistic regression. The result shows that all of the six domains are significant predictors of quality of life in Hawassa. And all of the six domains have positive impact on quality of life. For instance the higher the score in quality of public service, the better is the residents' quality of life in Hawassa. Carlos [13] reported that respondents that are satisfied or 'very satisfied' are generally pleased with the quality of service provision, while those who are 'unhappy' or 'very unhappy' are very negative about the quality of service they receive in South Africa.

Factor analysis is also used to identify the dimensions of the objective quality of life using fifteen attributes. The fifteen variables are reduced to six independent factors which constitute $71 \%$ of the total variation in the original data set. The factors are named as socio-economic domain score, access to public service domain score, access to education domain score, housing domain score, spirituality domain score and length of residence domain score. Elsa [9] identified 
five dimensions using 13 attributes for Krikos sub city of Addis Abeba. These dimensions are crowdedness, socio-economic, safety and proximity, housing and demographic. Most of the dimensions are related to the dimensions obtained from this study. Das [14] also identified seven dimensions of objective quality of life for the city of Guwahati using 27 attributes.

The six factors which are obtained from the factor analysis are used as independent variables to assess the impact they have on overall quality of life of the residents in Hawassa. It is found that neighborhood sanitation, access to education, housing, religion and length of residency to be statistically significant predictor of quality of life. But it is found that access to public service is not significant predictor of quality of life. This contradicts with the result of Sedigheh [15] who reported that the provision of public services have great influence on urban quality of life. The non significance of access of public service in this study may be related to the respondent's falsity in knowing the exact distance of their house from different public services. Housing and length of residency have positive impact on quality of life. This implies that the higher the score in housing and length of residency, the better the quality of life. Socio-economic, distance to educational centers and access to religious place has negative contribution to quality of life. The higher the score in these dimensions, the lower the quality of life. This result is also well supported by Javad [16] who reported that an increase in an economic index would probably increase the quality life of Kosar and Saber residents.

\section{Conclusions}

Housing domain, economic domain, environmental domain, neighborhood safety and security domain, social connectedness domain and quality of public service domain are identified as dimensions of subjective quality of life of the residents in Hawassa. All of the domain scores are found to be significant predictors of the residents' quality of life. The higher the score in the above domains, the better is the residents' quality of life.

Socio-economic domain, access to public service domain, access to education domain, housing domain, access to religious place domain and length of residency domains are found to be the dimensions of the objective quality of life of the residents in Hawassa. Finally, we directly considered all the objective domain scores to explain quality of life and it is found that neighborhood sanitation, distance to educational centers, housing, religion and length of residence are significant predictors of quality of life. But access to public service is not significant predictor of quality of life of the residents in Hawassa. Housing and length of residency have positive impact on quality of life which implies that the higher the score in housing and immovability, the better the quality of life. Socio-economic, access to education and religion has negative contribution to quality of life. The higher the score in these dimensions, the lower is the quality of life.

\section{List of Abbreviations}

$\begin{array}{ll}\text { HR QOL } & \begin{array}{l}\text { Health Related Quality of Life } \\ \text { Objective Quality of Life } \\ \text { OQOL }\end{array} \\ \text { QOL } & \text { Quality of Life } \\ \text { SNNPR } & \begin{array}{l}\text { Southern Nation, Nationalities and Peoples of } \\ \text { Region }\end{array} \\ \text { SPSS } & \text { Statistical Package for social Science } \\ \text { SQOL } & \text { Subjective Quality of Life } \\ \text { UQOL } & \text { Urban Quality of Life }\end{array}$

\section{Authors' Contributions}

The author contributed to the design of the study and the interpretation of data, performed the data analysis and drafted the manuscript. The author also critically revised the draft manuscript and have read and approved the final manuscript.

\section{Acknowledgements}

Firstly I would like to thank my almighty god for giving me the opportunity to study at Hawassa University and to complete the thesis work. This thesis would not have been possible without God's will and permission. And then I would like to extend my gratitude to Hawassa University for providing the funding for this study. I am also grateful to my advisor Butte Gotu, PhD, president of Alpha university college, Addis Ababa, Ethiopia for his advice and support. Last but not least, I would like to give my special thanks to my friend Engida Yisma, Lecturer in School of Nursing and Midwifery, College of Medicine and Health Sciences, Samara University, Samara, Ethiopia for his technical support.

\section{References}

[1] Andrews, F. M. \& Withey, S. B: Social Indicators of Well-being: American's Perception of Life Quality. New York, Plenum Press; 1976.

[2] Foo,T:: Subjective Assessment of Urban Quality of Life in Singapore (1997-1998).Habitat International, 24(1):31-49; 2000.

[3] Bradshaw, Y. and Fraser, E.: City Size, Economic Development and Quality Of Life in China: New Empirical Evidence, China; 1987.

[4] Habtamu Wondimu: Quality of Life, Poverty and Inequality in Ethiopia;2000.

[5] Aklilu Kidanu and Dessalegne Rahmato: Listening to the Poor. AA: FSS; 2000.

[6] Aweke Abebaw: Statistical Analysis of Health Related Quality of Life of HIV Patients on ART in Hawassa University Referral Hospital: A Comparative Study to the General Population. M.Sc. Thesis, Department of Mathematical and Physical Sciences, Hawassa University, Hawassa, Ethiopia; 2010.

[7] Abinet Alemayehu, Assefa Getachew, and Alemu Tadesse: Hawassa City Administration: 2002 Socio-economic Profile. Hawassa, Ethiopia; 2002.

[8] Cochran, W.G.: Sampling Techniques. Third Edition, John Wiley and Sons (ASIA) pte Ltd., Singapore, pp. 428; 1977. 
[9] Elsa Sereke: Urban Quality of Life and its Spatial Distribution in Addis Abeba: Krikos Sub-city. M.Sc.Thesis, Department of Geo-information Science and Earth Observation, Enschede University, Netherland; 2009.

[10] Ibrahim,M. Chung,W: Quality of life of residents living near industrial states in singapore. Social Indicators Research, 61:207-225; 2003.

[11] Matjoba S, Iman A, Amin M, Aram K, Ayda A: Analysis of subjective indicators of Quality of life in urban areas of Iran. Journals of research in humanities and social science, 3:39-46; 2015

[12] Akram,A. Hojjat A, and Hossein G.: Analysis urban life quality, case study residents of Rostamabad City. American Journal of Engineering Research (AJER),3:322-329; 2014
[13] Carlos, M.: Quality of Life in Urban Neighborhoods in Colombia: The Cases of Bogotá and Medellín, Colombia; 2008.

[14] Das, D.: Urban Quality of Life: A Case Study of Guwahati. Social Indicators Research, 88:297-310, Guwahati, India; 2008.

[15] Sedigheh, L. and Karim, S.: An Assessment of Urban Quality Of Life by Using Analytic Hierarchy Process Approach: A Comparative Study of Quality of Life in the North of Iran. ISSN 1549-3652; 2009.

[16] Javad, B. and Mohammed, A.: A comparative study of the quality of urban life: the case study of Mashhad neighborhoods. Journal of novel applied statistics, 9:387-397:2013. 